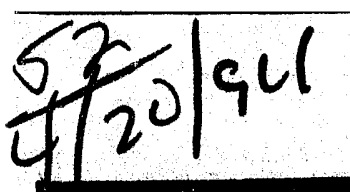

\section{PPPL-2968}

- UC-420,426
PREPARED FOR THE U.S. DEPARTMENT OF ENERGY, UNDER CONTRACT DE-AC02-76-CHO-3073

STABILIZATION AND ONSET OF SAWTEETH IN TFTR

BY

F.M. LEVINTON, L. ZAKHAROV, S.H. BATHA, ET AL.

MARCH, 1994
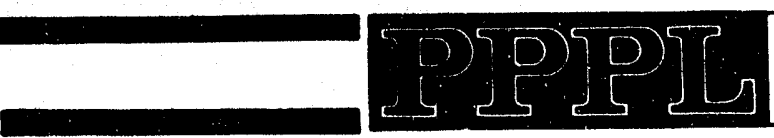

PRINCETON

plasma physics

LABOAATEAY

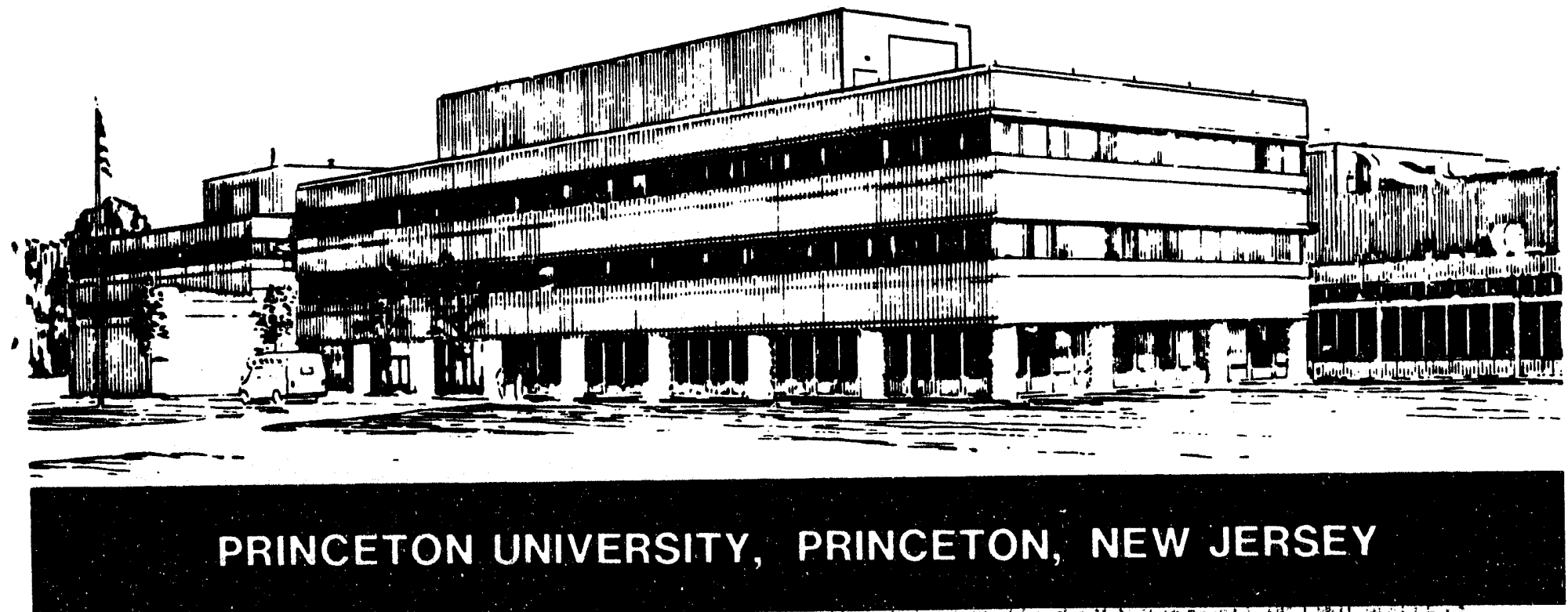




\section{NOTICE}

This report was prepared as an account of work sponsored by an agency of the United States Government. Neither the United States Government nor any agency thereof, nor any of their employees, makes any warranty, express or implied, or assumes any legal liability or responsibility for the accuracy, completeness, or usefulness of any information, apparatus, product, or process disclosed, or represents that its use would not infringe privately owned rights. Reference herein to any specific commercial produce, process, or service by trade name, trademark, manufacturer, or otherwise, does not necessarily constitute or imply its endorsement, recommendation, or favoring by the United States Government cr any agency thereof. The views and opinions of authors expressed herein do not necessarily state or reflect those of the United States Government or any agency thereof.

\section{NOTICE}

This report has been reproduced from the best available copy. Available in paper copy and microfiche.

Number of pages in this report: 16

DOE and DOE contractors can obtain copies of this report from:

Office of Scientific and Technical Information

P.O. Box 62

Oak Ridge, TN 37831;

(615) $576-8401$.

This report is publicly available from the:

National Technical Information Service

Department of Commerce

5285 Port Royal Road

Springfield, Virginia 22161

(703) $487-4650$ 


\title{
Stabilization and onset of sawteeth in TFTR
}

\author{
F. M. Levinton ${ }^{1}$, L. Zakharov ${ }^{2}$, S. H. Batha ${ }^{1}$, J. Manickam ${ }^{2}$, M. C. Zarnstorff ${ }^{2}$ \\ ${ }^{1}$ Fusion Physics and Technology, Torrance, CA 90503-1673 \\ ${ }^{2}$ Princeton Plasma Physics Laboratory, P. O. Box 451, Princeton, NJ 08543-0451
}

(February 26, 1994)

\begin{abstract}
Measurements from the Tokamak Fusion Test Reactor (TFTR) of the $q$-profile using motional Stark effect (MSE) polarimetry and the pressure profiles have allowed detailed comparison of both supershots and L-mode discharges to theoretical models describing the stability of sawteeth. In TFTR supershots sawteeth are usually absent, whereas in L-mode discharges they are generally present, and in both cases $q(0)$ is less than one. It has been found that the $\omega^{*}$-stabilization criterion of the two-fluid collisionless $m=1$ reconnection mode agrees very well with the presence or absence of sawteeth in TFTR and no beta limits to the sawtooth stabilization have been observed.
\end{abstract}

52.55.Fa, 52.35.Py, 52.30.Jb

Typeset using REVTEX

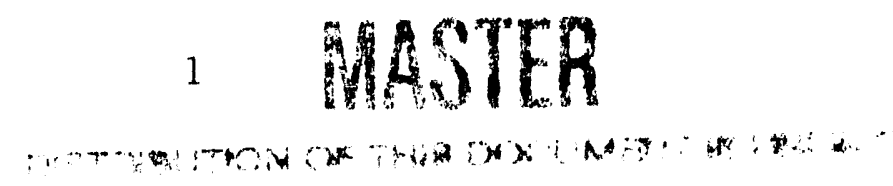


Sawtooth oscillations [1] are characterized by a periodic collapse of the pressure in the plasma core. They have been the subject of extensive experimental and theoretical investigations because of their relation to several fundamental properties in plasmas, such as magnetohydrodynamic(MHD) phenomena, magnetic reconnection, and perhaps plasma disruptions. There are several theoretical models $[2,3]$ which predict that when the central safety factor, $q(0)$, is less than one, the plasma is unstable to the $m=1 / n=1$ reconnection mode which is responsible for observed sawteeth. A similar result is obtained for the ideal $\mathrm{m}=1$ internal kink, with the modification that $q(0)<1$ and $\beta_{1, \text { pol }}$ must exceed some threshold value [4] before the mode becomes unstable. Various theories are distinguished by the evolution or change in $q(0)$ after a sawtooth crash, the criteria for stabilizing the mode, and the dynamics of the magnetic reconnection during the crash.

Stabilization of sawteeth has been observed on several devices [5-8]. A number of mechanisms for stabilization have been suggested, but no clear understanding has emerged. In this Letter we present a comparison of data to the two-fluid model for sawtooth stabilization, both for discharges with and without sawteeth, that have $q(0)<1$. We have found that for the one-fluid ideal and resistive MHD models the $m=1 / n=1$ mode is always unstable, contradicting the experimental data. However, the two-fluid collisionless $m=1$ reconnection model $[9,10]$, which is a resistive internal kink in the high temperature regime, has an $\omega^{*}$ stabilization effect that agrees very well with data from TFTR during neutral beam heating if we neglect the effect of the ideal mode.

Only recently, with routine $q$-profile measurements, has a quantitative comparison of theoretical sawtooth models with experimental data become possible. On the Tokamak Fusion Test Reactor (TFTR) [11], a multichannel motional Stark effect polarimeter (MSE) [12,13] can measure the local magnetic field pitch angle, $\tan \left(\gamma_{p}\right)=B_{p} / B_{t}$, in the midplane at 10 spatial locations with a time resolution of $\geq 3 \mathrm{~ms}$. The circular geometry of TFTR simplifies the conversion of pitch angle to $q(R)$ [13] and equilibrium reconstruction, making a more accurate comparison to theoretical models possible. The temperature and density profiles, which are also essential for stability analysis, are measured using charge exchange recombi- 
nation spectroscopy(CHERS) for ion temperature profiles, electron cyclotron emission(ECE) and Thomson scattering for electron temperature profiles, multichord FIR interferometry and Thomson scattering for electron density profiles, and visible bremsstrahlung for $Z_{\text {eff }}$ profiles. The fast ion pressure due to neutral beam injection(NBI) is calculated with a Monte-Carlo simulation in a $1 \frac{1}{2}$-D transport code (TRANSP) [14], which utilizes the kinetic and magnetics data to determine the equilibria. The MSE data, along with the kinetic profile data, have been incorporated into a fixed boundary equilibrium solver [15] to calculate the current density and $q$-profile.

The data from TFTR either have sawteeth, are sawtooth stable, or make a transition between the two states. The sawteeth can be clearly identified with the ECE diagnostic which is very sensitive to temperature fluctuations and sawtooth activity. Our experience on TFTR has been that when sawteeth are present, $q(0)$ is less than one. However, the converse is not true: when $q(0)<1$, sawteeth are not necessarily present. Shown in Fig. 1 is an example of the evolution of $q(0)$ during the neutral beam heating phase for both a supershot without sawteeth and an L-mode discharge with sawteeth. In both cases $q(0)$ is less than one with no discernable difference in its evolution. Sawteeth are present during the ohmic phase, but disappear shortly after the neutral beams are turned on for the supershot example. In both discharges the plasma current was $1.8 \mathrm{MA}$ and auxiliary neutral beam input power was $17 \mathrm{MW}$ for $1.5 \mathrm{~s}$. The line averaged density for the supershot was $25 \%$ lower, and had a factor of two larger peak pressure. Both discharges also have similar $\mathrm{m}=1 / \mathrm{n}=1$ MHD modes, about $15 \mathrm{~cm}$ in width, which in the sawtoothing discharge appears as a precursor to a sawtooth crash, and in the non-sawtoothing supershot is a saturated $\mathrm{m}=1 / \mathrm{n}=1$ mode for the last half of the NBI phase of the discharge. During the first half of the NBI phase there is no $m=1$ MHD mode present. All the sawtooth stable discharges in this series have $q(0)<1$ with little or no MHD activity. When the $\mathrm{m}=1$ mode is present it is saturated at a low level. It is also noteworthy that even when sawteeth are present, $q(0)$ remains below one throughout the discharge. The small measured change in the $q$-profile and $q(0)$ during the sawtooth crash implies that a full magnetic reconnection cannot occur, 
which is contrary to many sawtooth models such as the Kadomtsev model [2]. These results are described in more detail in Ref. [13].

We have also looked for small-scale structure $(\sim 1-2 \mathrm{~cm})$ in the $q$-profile, such as a low shear region near the $\mathrm{q}=1$ radius which has been predicted theoretically [16] to stabilize the $\mathrm{m}=1$ mode. This was suggested as the mechanism responsible for the sawtooth stabilization observed in the TEXTOR [17] tokamak. Low shear in the $q$-profile and flat spots in the electron temperature profile could be observed in TFTR by moving the plasma radially several centimeters, which would allow structures of order $1-2 \mathrm{~cm}$ to be observed $[13,18]$. This technique allows the gradient to be measured by a single detector which removes systematic uncertainties and greatly improves the spatial resolution. The results from this study do not show any flattening or other structure near the $q=1$ radius, whether or not sawteeth are present.

Sawtooth stabilization by fast particles, as has been observed for RF heated plasmas [19], is not likely since the neutral beams are injected tangentially and would produce few trapped ions for fast particle stabilization [20-22].

Supershot data are characterized by peaked pressure profiles, and they are usually sawtooth free. L-mode discharges typically have sawteeth with a broader pressure profile and a lower peak pressure. These tendencies are the opposite of what one would expect based on linear ideal or resistive MHD theories, where pressure gradients are more de-stabilizing to the $\mathrm{m}=1 / \mathrm{n}=1$ mode. For typical sawtooth stable supershots the central $\beta_{1, p o l}$ is $\sim 1-2$, which is much higher than the theoretical threshold of 0.3, derived by Bussac [4], for excitation of the ideal MHD $m=1$ mode, where $\beta_{1, p o l}$ is defined as,

$$
\beta_{1, p o l}=\frac{8 \pi\left[<p>-p\left(r_{1}\right)\right]}{B_{\theta}^{2}\left(r_{1}\right)}
$$

Here, $\langle p\rangle$ is the total plasma pressure averaged over the volume inside the $q=1$ radius and $B_{\theta}\left(r_{1}\right)$ is the poloidal field at $r=r_{1}$, where $r_{1}$ is the radius at the $q=1$ surface. Both the L-mode and supershot discharges are calculated to be unstable to the ideal $\mathrm{m}=1$ mode using both the analytic Bussac criterion as well as a numerical stability calculation with the 
PEST code [23].

In TFTR, with electron temperatures of $5-12 \mathrm{keV}$ and ion temperatures of $\leq 35 \mathrm{keV}$ the single-fluid resistive MHD model is questionable. The ion Larmor radius $(\sim 5 \mathrm{~mm})$ as well as the collisionless skin depth, $d_{e}=c / \omega_{p e}(\sim 0.8 \mathrm{~mm})$ are larger than the resistive singular layer, $\Delta_{\eta} \sim r_{1} \tau_{\text {rec }} / 4 \tau_{\eta} \sim 0.02 \mathrm{~mm}$, where $\tau_{\text {rec }}$ is the reconnection time and $\tau_{\eta}$ is the resistive diffusion time. In this regime the $m=1$ mode is in the modified [24] collisionless regime and can be described by a kinetic [25] or two-fluid model $[9,10]$. Both result in diamagnetic effects that can stabilize the collisionless $m=1$ reconnection mode due to the relative motion between the magnetic perturbation and the plasma that provides additional inertia for stabilization. The resulting stability criterion can be written in a symbolic form,

$$
r_{1} q_{c r}^{\prime}>r_{1} q_{1}^{\prime}
$$

where $r_{1} q_{1}^{\prime}$ is the shear at the $\mathrm{q}=1$ radius and $r_{1} q_{c r}^{\prime}$ is the critical shear for stabilization, which depends on the local gradients and pressure at the $q=1$ surface and the ideal mode characteristic singular layer width, $\lambda_{H}$.

In the analysis, $r_{1} q_{c r}^{\prime}$ has been calculated numerically by solving the dispersion relation of the two-fluid MHD model [9]. To be consistent with the fluid model we include the beam particles in the ion species. If the linear ideal MHD mode is included in the dispersion relation for the growth rate [cf Eq. (26) of Ref. [9] with $\lambda_{H} \neq 0$ ] the $\mathrm{m}=1$ mode is found to be always unstable, contradicting the experimental data. But, if we assume that the perturbation due to the $m=1$ mode nonlinearly saturates and can neglect for that reason the ideal kink mode $\left(\lambda_{H}=0\right)$, then the criterion in Eq. (2) below is consistent with the experimental data. Indeed, the $m=1$ mode is observed experimentally to saturate at low amplitude when it is present at all. Then with $\lambda_{H}=0$ the criterion in Eq. (1) is approximately [cf. Eq.(39) of Ref. [10]],

$$
r_{1} q_{c r}^{\prime} \simeq 1.4\left(\frac{m_{i}}{2 m_{p} Z_{\text {eff }}}\right)^{1 / 6} \beta_{1}^{2 / 3}\left(\frac{\left|n_{e}^{\prime}\right| R}{n_{e}}\right)^{2 / 3}\left(\frac{\left|p^{\prime}\right| R}{p}\right)^{1 / 3}>r_{1} q_{1}^{\prime} .
$$

All quantities are evaluated at $r_{1}$, and $\beta_{1}$ is the toroidal beta at $r_{1}, n_{e}$ the electron density, $m_{p}$ the proton mass, $R$ the major radius, $p$ the total plasma pressure, including the fast 
ion pressure and $q_{1}^{\prime}=d q(r) /\left.d r\right|_{r=r_{1}}$. Note that for $T_{i}^{\prime}=T_{e}^{\prime}=0$, the criterion in Eq. (1) corresponds to the condition $\omega_{i}^{*}>\gamma_{0}$ of Ref. [25]. In contrast to ideal MHD theory for the $m=1$ mode, the pressure gradient in Eq. (2) is stabilizing while the shear is de-stabilizing.

In the analysis, the measured kinetic profiles and the calculated fast ion pressure from the TRANSP code are used to calculate the parameter $r_{1} q_{c r}^{\prime}$, while the MSE data is used to determine the $q$-profile and shear. The estimated uncertainty of $r_{1} q_{1}^{\prime}$ and $r_{1} q_{c r}^{\prime}$ is $\sim 0.05-0.1$. This is based on the propagation of the systematic and statistical uncertainties in the MSE data in the equilibrium reconstruction.

The stability criterion in Eq. (2) is in good agreement with all data analyzed to date. Shown in Fig. 2 is the time evolution of the shear, $r_{1} q_{1}^{\prime}$, and the critical shear, $r_{1} q_{c r}^{\prime}$, from Eq. (2), for three discharges. The first discharge, with a plasma current of $1.8 \mathrm{MA}$ and NBI power of $10 \mathrm{MW}$, has sawteeth throughout its duration (Fig. 2(a)). The critical shear, $r_{1} q_{c r}^{\prime}$, is less than the measured shear, $r_{1} q_{1}^{\prime}$, which correctly predicts this discharge to have sawteeth. Fig. 2(b) depicts a similar discharge to that shown in Fig. 2(a), except the plasma current was reduced to 1.4 MA. This resulted in a more peaked presoure profile and broader $q$-profile, as shown by the quantities $r_{1} q_{c r}^{\prime}$ and $r_{1} q_{1}^{\prime}$. This discharge was correctly predicted to be sawtooth-stable. In another case, a 1.4 MA supershot was purposely degraded to Lmode with a large puff of helium gas during the NBI phase of the discharge. The plasma was sawtooth-free until shortly after the helium was added at $4.2 \mathrm{~s}$, after which the confinement deteriorated and sawteeth began to occur. The time evolution of $r_{1} q_{c r}^{\prime}$ and $r_{1} q_{1}^{\prime}$ is shown in Fig. 2(c). The stability criterion predicts a stable discharge between $t=3.8 \mathrm{~s}$ and $4.33 \mathrm{~s}$. This is consistent with the data, which has the last sawtooth after the ohmic phase at $3.76 \mathrm{~s}$ and is stable until the sawteeth begin again at $4.47 \mathrm{~s}$. In this example, the last sawtooth after the ohmic phase occurs before the stability criterion changes from unstable to stable. The time delay is less than one sawtooth period, which is typically $0.15-0.3 \mathrm{~s}$ during the NBI phase. Similarly, the stability criterion changes from stable to unstable before the sawteeth resume, and again, the difference in time is less than one sawtooth period. This suggests that even though the mode is unstable there is a finite period of time, consistent with the sawtooth 
period, that is required to trigger the sawtooth crash. An analysis of many shots for the entire evolution of the NBI phases of the discharge has been performed on the TFTR data where both the MSE and kinetic data are available for calculation of the stability criterion. The data include cases with $q(0)$ in the range of $0.7-0.95$ for both L-mode and supershot conditions, and plasma currents of $1.4-2.0 \mathrm{MA}$ and neutral beam power of $10-18 \mathrm{MW}$. The results are shown in Fig. 3. The region in the upper part of the graph, with $r_{1} q_{c r}^{\prime}>r_{1} q_{1}^{\prime}$, should be sawtooth-stable, while the region below the line should be sawtooth-unstable. The data points are plotted according to their calculated values of $r_{1} q_{c r}^{\prime}$ and $r_{1} q_{1}^{\prime}$, and their symbols indicate whether or not there were sawteeth at the time. All the data agree very well with the criterion within the uncertainty of the calculated quantities. One data point which stands out that is calculated to be stable when it is not is interesting because it is the only case that has "fishbone" bursts, that is high frequency bursts observed on the external magnetic coils, which are often accompanied by a loss of fast ions $[26,27]$. This may not be too surprising, since the calculation of the fast ion pressure does not allow for the loss of the ions due to the fishbone mode. At $r_{1}$, the fast ion pressure is calculated to be $40 \%$ of the total pressure. If the fast ion loss were included the pressure would be reduced, lowering the data point closer to or perhaps below the stability boundary.

In conclusion we have observed stabilization of sawteeth that are not due to fast particles or small scale structure in the $q$-profile, such as low shear near the $q=1$ radius. Based on the extremely good agreement of the stabilization criterion of Eq. (2) with the presence, absence, or onset of sawteeth, we can conclude that the $\mathrm{m}=1$ two-fluid collisionless reconnection mode is responsible for sawtooth oscillations observed in tokamak plasmas. We have a set of data covering a wide region of operational parameter space in which the model works, when the ideal mode is ignored, including both sawtoothing and sawtooth-free discharges for the entire NBI phase(up to $2 \mathrm{~s}$ ). In contradiction to linear ideal MHD theory we see no beta limit to sawtooth stabilization. In all cases the linear ideal and resistive single fluid theories predict the mode to be unstable, including many examples which are sawtooth stable.

There are still several outstanding issues that have not been addressed in this model, such 
as the sawtooth period and the change in the central current density or $q(0)$. Measurements in TFTR have shown that the change in $q(0)$ after a sawtooth crash is small $(\leq 0.1)$, and $q(0)$ remains below one throughout the sawtooth evolution [13]. This implies that the reconnection is only partial; perhaps some mechanism prevents the full reconnection of flux. This has to be reconciled with the observation that the flattening of the pressure profile after a sawtooth crash extends to the plasma center. These results may help guide theory and lead to a better understanding of reconnection phenomena, MHD stability, and perhaps plasma disruptions in high temperature plasmas.

\section{ACKNOWLEDGMENTS}

The authors would like to thank E. Fredrickson, B. Grek, H. Park, A. Ramsey, E. Synakowski, G. Taylor, and the TFTR staff for there support and operation of the tokamak. This work was supported by United States Department of Energy Contract No. DE-AC0276-CHO-3073. 


\section{REFERENCES}

[1] S. von Goeler, W. Stodiek, and N. Sauthoff, Phys. Rev. Lett. 33, 1201 (1974).

[2] B. B. Kadomtsev, Sov. J. Plasma Phys. 1, 389 (1975).

[3] B. Coppi et al., Sov. J. Plasma Phys. 2, 533 (1976).

[4] M. N. Bussac, R. Pellat, D. Edery, and J.L.Soule, Phys. Rev. Lett. 35, 1638 (1975).

[5] K. McGuire et al., Coherent and Turbulent Fluctuations in TFTR (International Atomic Energy Agency, Vienna, 1987), Vol. I, p. 421.

[6] TFR Group, Nucl. Fusion 28, 1995 (1988).

[7] K. Hanada et al., Phys. Rev. Lett. 66, 1974 (1991).

[8] D. J. Campbell et al., Phys. Rev. Lett. 60, 2148 (1988).

[9] L. Zakharov and B. Rogers, Phys. Fluids B 4, 3285 (1992).

[10] L. Zakharov, B. Rogers, and S. Migliuolo, Phys. Fluids B 5, 2498 (1993).

[11] D. M. Meade and the TFTR group, Plasma Physics and Controlled Nuclear Fusion Research, Washington, D. C. 1990 (International Atomic Energy Agency, Vienna, 1991), Vol. I, pp. 9-24.

[12] F. M. Levinton et al., Phys. Rev. Lett. 63, 2060 (1989).

[13] F. M. Levinton, S. H. Batha, M. Yamada, and M. C. Zarnstorff, Phys. Fluids B 5, 2554 (1993).

[14] R. J. Hawryluk, Proc. Course in Physics of Plasmas Close to Thermonuclear Conditions, Varenna 1979 (CEC, Brussels, 1980), Vol. I, p. 19.

[15] L. E. Zakharov, Technical Report No. IAE-4114/6, Kurchatov Institute of Atomic Energy, Moscow(1985). 
[16] J. A. Holmes, B. A. Carreras, and L. A. Charlton, Phys. Fluids B 1, 788 (1989).

[17] H. Soltwisch, W. Stodiek, J. Manickam, and J. Schluter, Plasma Physics and Controlled Nuclear Fusion Research, Kyoto, 1986 (International Atomic Energy Agency, Vienna, 1987), Vol. I, p. 263.

[18] M. C. Zarnstorff et al., Submitted for publication.

[19] C. K. Phillips et al., Phys. Fluids B 4, 2155 (1992).

[20] R. B. White, M. N. Bussac, and F. Romanelli, Phys. Rev. Lett. 62, 2733 (1989).

[21] B. Coppi et al., Phys. Rev. Lett. 63, 2733 (1989).

[22] F. Porcelli, Plasma Phys. Controlled Fusion 33, 1601 (1991).

[23] R. C. Grimm, R. L. Dewar, and J. Manickam, J. Comput. Phys. 49, 94 (1983).

[24] J. F. Drake, Phys. Fluids 21, 1777 (1978).

[25] F. Porcelli, Phys. Rev. Lett. 66, 425 (1991).

[26] K. McGuire et al., Phys. Rev. Lett. 50, 891 (1983).

[27] R. Kaita et al., Phys. Fluids B 2, 1584 (1990). 


\section{FIGURES}

FIG. 1. The $q(0)$ evolution for both a supershot without sawteeth(solid line) and a L-mode discharge with sawteeth(dashed line). Neutral beam heating is from 3.0 to $4.5 \mathrm{~s}$.

FIG. 2. The critical shear, $r_{1} q_{c r}^{\prime}$, and shear, $r_{1} q_{1}^{\prime}$, for three cases. In (a) is an L-mode discharge with sawteeth. In (b) is a supershot without sawteeth. In (c) the discharge starts off as a supershot without sawteeth and is spoiled to an L-mode with sawteeth. The discharge is sawtooth free from $\mathrm{t}=3.76 \mathrm{~s}$ to $4.47 \mathrm{~s}$

FIG. 3. The critical shear, $r_{1} q_{c r}^{\prime}$, and shear, $r_{1} q_{1}^{\prime}$, from several discharges, each at several different times during a discharge. The data consist of both L-mode and supershots with $q(0)<1$. Cases where sawteeth are present have open circles and when absent have solid circles. 


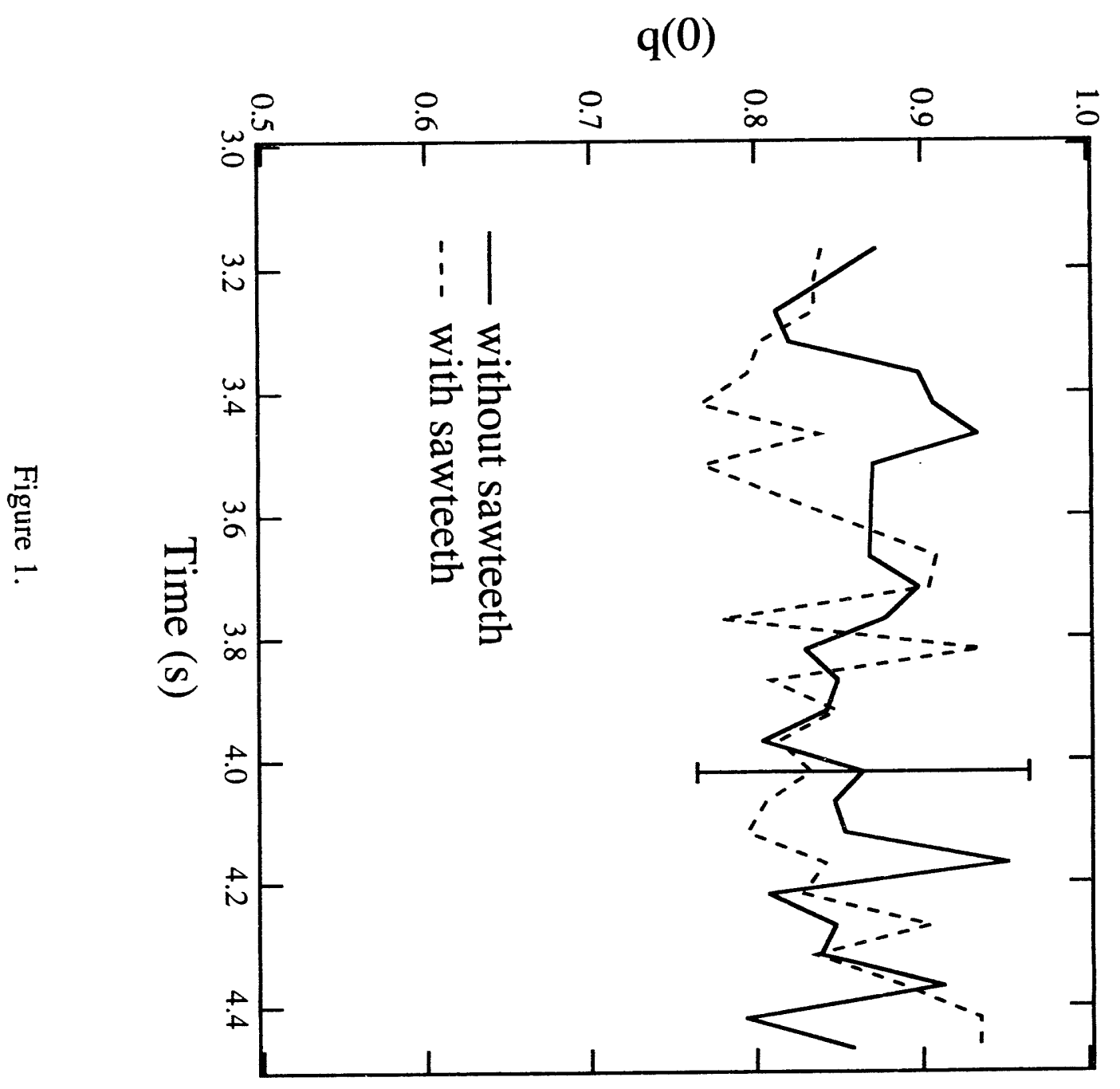



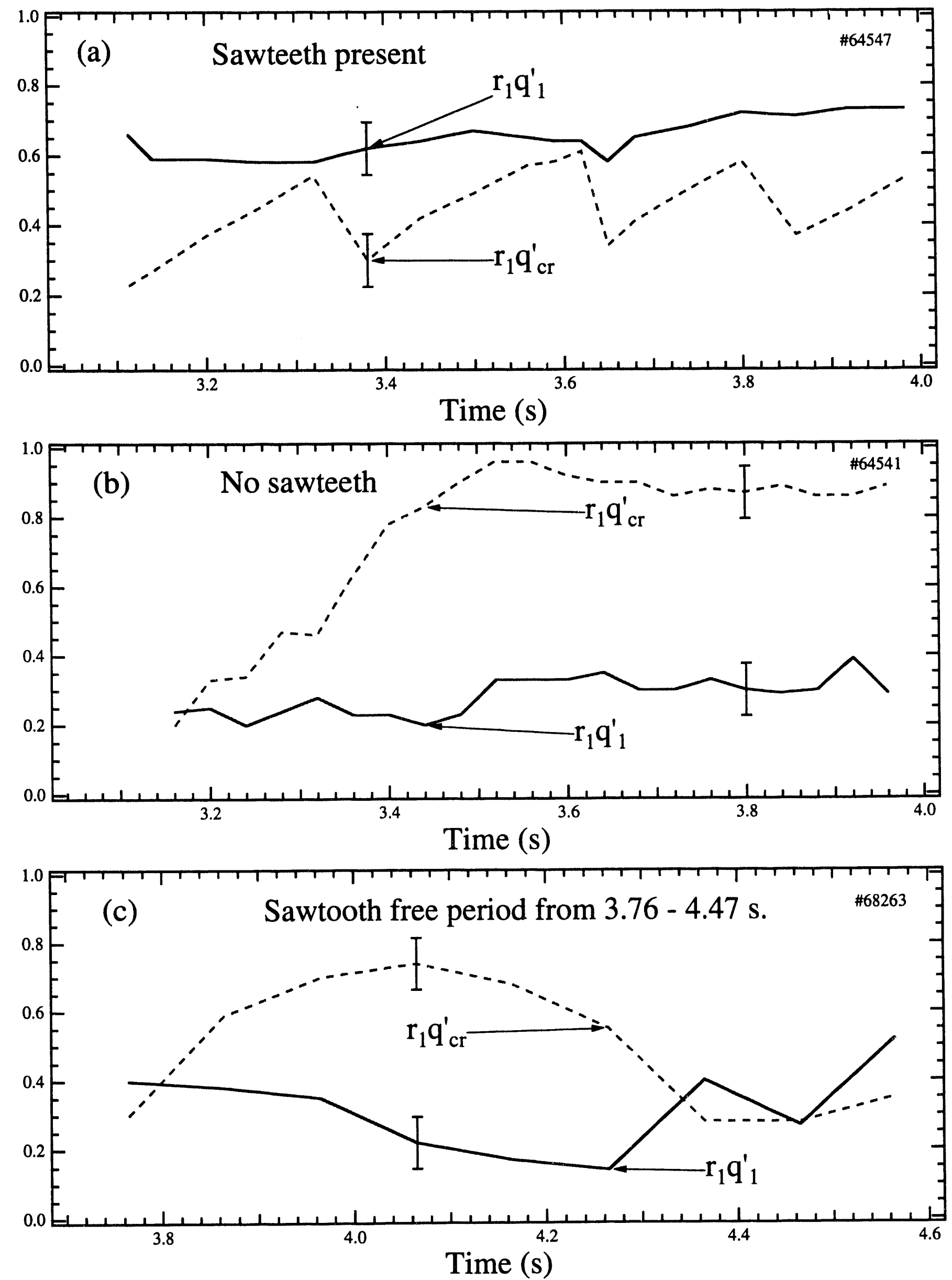

Figure 2. 


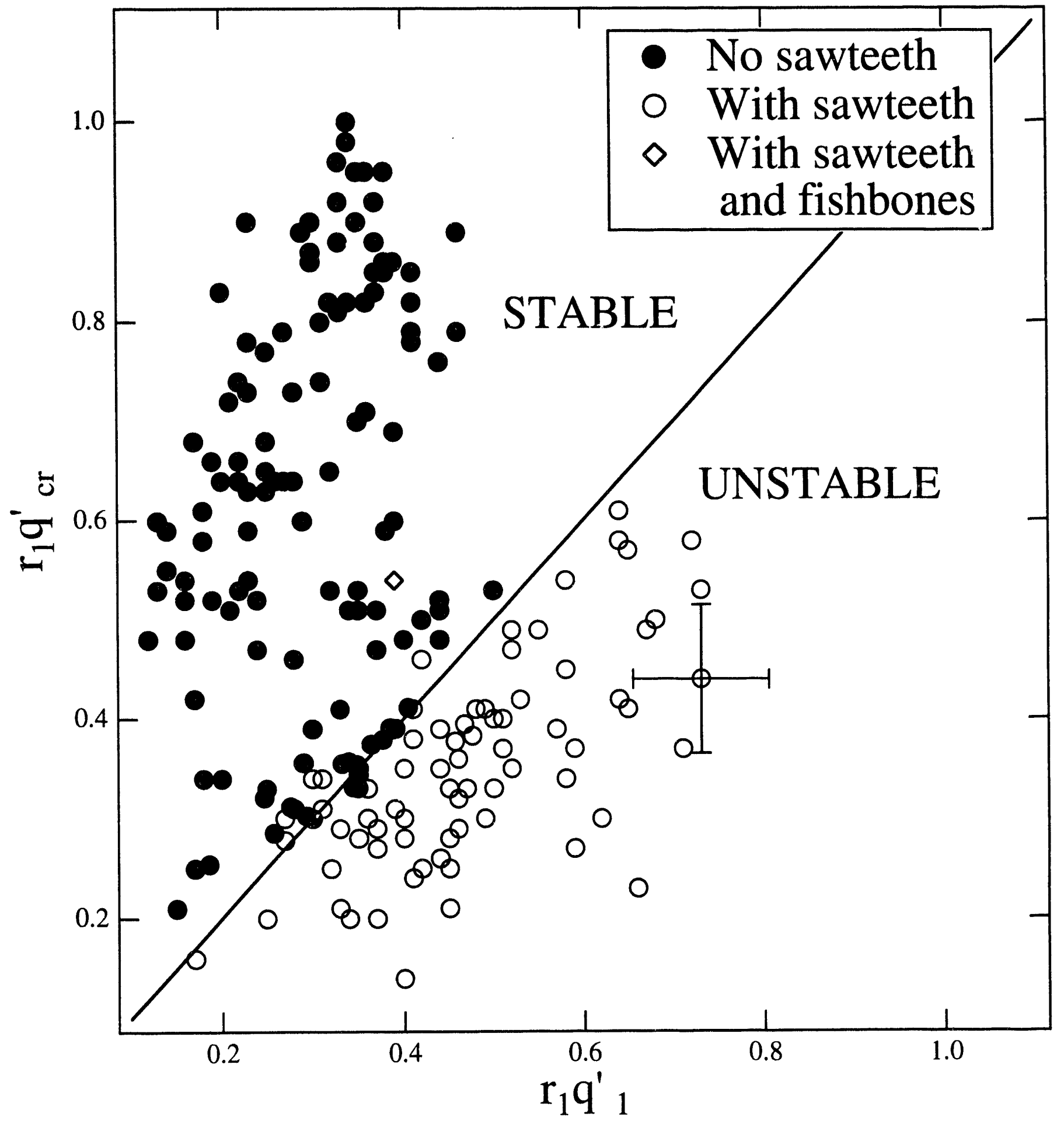

Figure 3. 
Dr. F. Paoloni, Univ. of Wollongong, AUSTRALIA

Prof. M.H. Bronnan, Univ. of Sydney, AUSTRALIA

Plasma Research Lab., Australian Nat. Univ., AUSTRALIA

Prof. I.R. Jones, Flinders Univ, AUSTRALIA

Prof. F. Cap, Inst. for Theoretical Physics, AUSTRIA

Prof. M. Heindler, Institut für Theoretische Physik, AUSTRIA

Prof. M. Goossens, Astronomisch Instituut, BELGIUM

Ecole Royale Militaire, Lab. de Phy. Plasmas, BELGIUM

Commission-European, DG. XII-Fusion Prog., BELGIUM

Prof. R. Bouciqué, Rijksuniversiteit Gent, BELGIUM

Dr. P.H. Sakanaka, Instituto Fisica, BRAZIL

Prof. Dr. I.C. Nascimento, Instituto Fisica, Sao Paulo, BRAZIL Instituto Nacional De Pesquisas Espaciais-INPE, BRAZIL

Documents Office, Atomic Energy of Canada Ltd., CANADA

Ms. M. Morin, CCFMTokamak de Varennes, CANADA

Dr. M.P. Bachynski, MPB Technologies, Inc., CANADA

Dr. H.M. Skarsgard, Univ. of Saskatchewan, CANADA

Prof. J. Teichmann, Univ. of Montreal, CANADA

Prof. S.R. Sreenivasan, Univ. of Calgary, CANADA

Prof. T.W. Johnston, INRS-Energie, CANADA

Dr. R. Bolton, Centre canadien de fusion magnétique, CANADA

Dr. C.R. James, Univ. of Alberta, CANADA

Dr. P. Lukác, Komenského Universzita, CZECHO-SLOVAKIA

The Librarian, Culham Laboratory, ENGLAND

Library, R61, Ruthertord Appleton Laboratory, ENGLAND

Mrs. S.A. Hutchinson, JET Library, ENGLAND

Dr. S.C. Sharma, Univ. of South Pacific, FIJI ISLANDS

P. Mähönen, Univ. of Helsinki, FINLAND

Prof. M.N. Bussac, Ecole Polytechnique,, FRANCE

C. Mouttet, Lab. de Physique des Milieux lonisés, FRANCE

J. Radet, CEN/CADARACHE - Bat 506, FRANCE

Prot. E. Economou, Univ. of Crete, GREECE

Ms. C. Rinni, Univ. of loannina, GREECE

Preprint Library, Hungarian Academy of Sa., HUNGARY

Dr. B. DasGupta, Saha Inst. of Nuclear Physics, INDIA

Dr. P. Kaw, Inst. for Plasma Research, INDIA

Dr. P. Rosenau, Israel Inst. of Technology, ISRAEL

Librarian, Intemational Center for Theo Physics, ITALY

Miss C. De Palo, Associazione EURATOM-ENEA, ITALY

Dr. G. Grosso, Istituto di Fisica del Plasma, ITALY

Prof. G. Rostangni, Istituto Gas Ionizzat Del Cnr, ITALY
C.. Yamato, Toshiba Res \& Devel Center, JAPAN

Prof. I. Kawakami, Hiroshima Univ., JAPAN

Prof. K. Nishikawa, Hiroshima Univ., JAPAN

Librarian, Naka Fusion Research Establishment, JAERI, JAPAN

Director, Japan Atomic Energy Research Inst., JAPAN

Prol. S. Itoh, Kyushu Univ., JAPAN

Research Info. Ctr., National Instit. for Fusion Science, JAPAN

Prof. S. Tanaka, Kyoto Univ., JAPAN

Library, Kyoto Univ., JAPAN

Prof. N. Inoue, Univ. of Tokyo, JAPAN

Secretary, Plasma Section, Electrotechnical Lab., JAPAN

S. Mori, Technical Advisor, JAERI, JAPAN

Dr. O. Mitarai, Kumamoto Inst. of Technology, JAPAN

Dr. G.S. Lee, Korea Basic Sci. Ctr., KOREA

J. Hyeon-Sook, Korea Atomic Energy Research Inst., KOREA

D.I. Choi, The Korea Adv. Inst. of Sci. \& Tech., KOREA

Prof. B.S. Liley, Univ. of Waikato, NEW ZEALAND

Inst of Physics, Chinese Acad Sci PEOPLE'S REP. OF CHINA

Library, Inst. of Plasma Physics, PEOPLE'S REP. OF CHINA

Tsinghua Univ. Library, PEOPLE'S REPUBLIC OF CHINA

Z. Li, S.W. Inst Physias, PEOPLE'S REPUBLIC OF CHINA

Prof. J.A.C. Cabral, Instituto Superior Tecnico, PORTUGAL

Prof. M.A. Hellberg, Univ. of Natal, S. AFRICA

Prof. D.E. Kim, Pohang Inst. of Sci. \& Tech., SO. KOREA

Prof. C.I.E.M.A.T, Fusion Division Library, SPAIN

Dr. L. Stenflo, Univ. of UMEA, SWEDEN

Library, Royal Inst. of Technology, SWEDEN

Prof. H. Wilhelmson, Chalmers Univ. of Tech., SWEDEN

Centre Phys. Des Plasmas, Ecole Polytech, SWITZERLAND

Bibliotheek, Inst. Voor Plasma-Fysica, THE NETHERLANDS

Asst. Prof. Dr. S. Cakir, Middle East Tech. Univ., TURKEY

Dr. V.A. Glukhikh,Sci. Res. Inst. Electrophys.I Apparatus, USSR

Dr. D.D. Ryutov, Siberian Branch of Academy of Sci., USSR

Dr. G.A. Eliseev, I.V. Kurchatov Inst., USSR

Librarian, The Ukr.SSR Academy of Sciences, USSR

Dr. L.M. Kovrizhnykh, Inst. of General Physics, USSR

Kernforschungsanlage GmbH, Zentralbibliothek, W. GERMANY

Bibliothek, Inst. Für Plasmaforschung, W. GERMANY

Prof. K. Schindler, Ruhr-Universitát Bochum, W. GERMANY

Dr. F. Wagner, (ASDEX), Max-Planck-Institut, W. GERMANY

Librarian, Max-Planck-Institut, W. GERMANY 

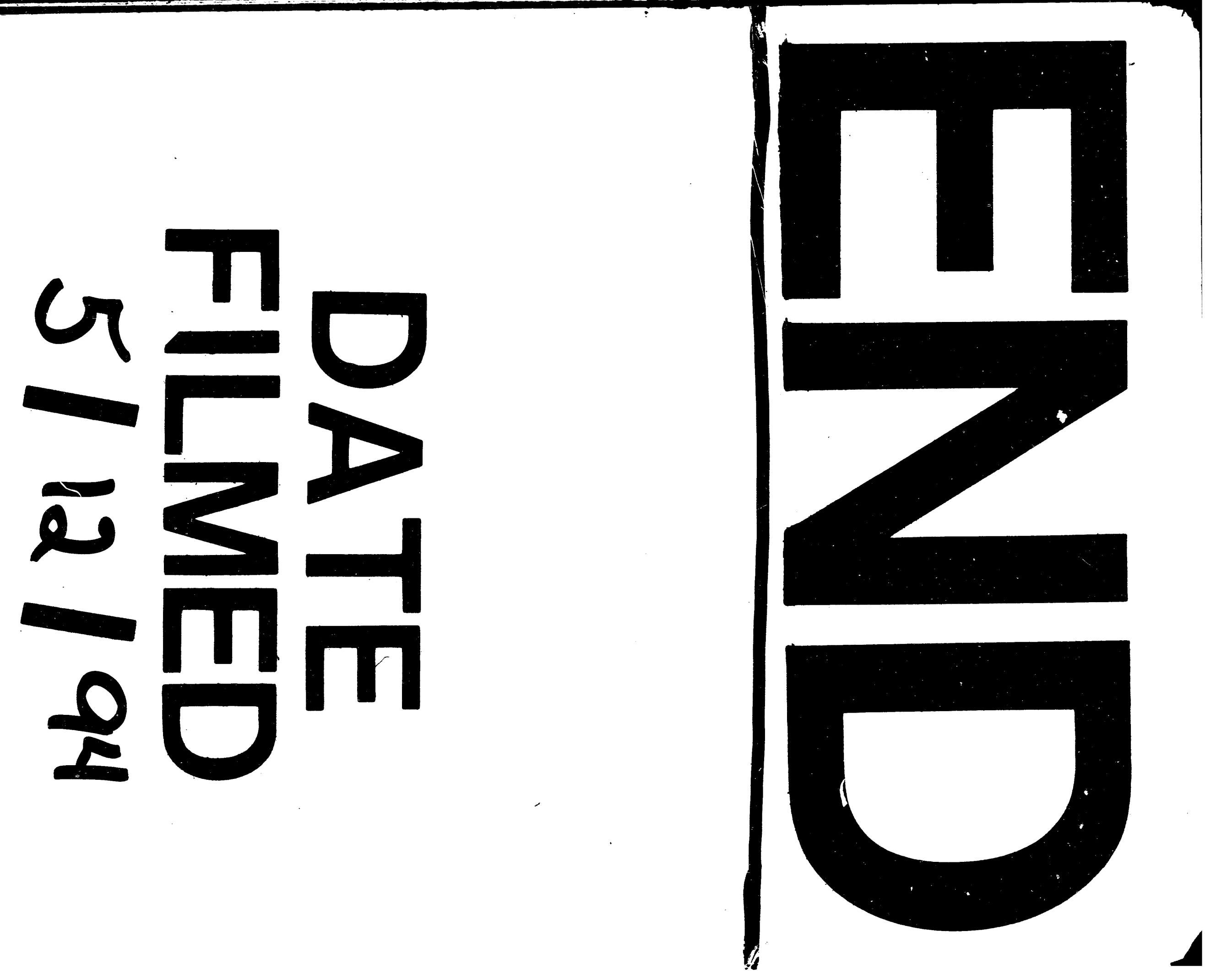


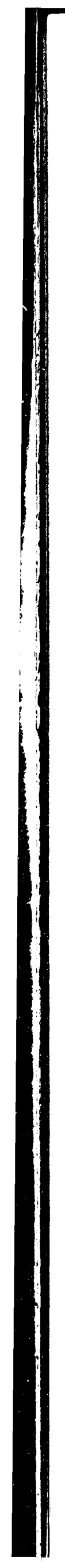

